\title{
Neuropathy associated with lymphoma
}

\author{
J. C. WALSH \\ From the Department of Medicine, University of Sydney, Royal Prince Alfred Hospital, Sydney, \\ and Repatriation General Hospital, Concord
}

SUMMARY Electrophysiological studies have been performed on 62 subjects with malignant lymphoma and the results compared with those of 35 control subjects matched for age. There was evidence of impairment of conduction consistent with a generalized peripheral neuropathy in 22 subjects $(35 \%)$. Histological and electronmicroscopic studies were performed on sural nerve biopsy material from five subjects, and the pathological abnormalities of the myelinated fibres were those of axonal degeneration and segmental demyelination. The unmyelinated fibres were not affected.

Since the description by Denny-Brown (1948) of a sensory neuropathy in two patients with carcinoma of the lung, there has been increasing awareness that the peripheral nervous system may be affected in this condition even when there is no clinical evidence of a peripheral neuropathy (Moody, 1965; Hildebrand and Coërs, 1967; Trojaborg, Frantzen, and Anderson, 1969). By contrast, peripheral neuropathy is a rarely reported complication of the malignant lymphomas (Hutchinson, Leonard, Maudsley, and Yates, 1958; Simpson, 1962). Although there have been isolated case reports of a peripheral neuropathy complicating these disorders, there has been no systematic investigation of randomly selected subjects with malignant lymphoma to determine the incidence of involvement of the peripheral nervous system. Moreover, there have been very few detailed pathological studies performed on the peripheral nervous system of affected patients.

The object of the present study has been to determine the incidence of impairment of nerve conduction in patients with malignant lymphoma, and to establish the nature of the pathological changes that may occur.

\section{METHOUS}

SUBJECTS Seventy-nine subjects with malignant lymphoma were examined. The diagnosis was confirmed by tissue biopsy in each case.

To exclude other causes of neuropathy a glucose tolerance test, urinary porphyrin assay, blood urea, bone 1Present address: Department of Medicine, University of Sydney,
New South Wales, Australia. marrow biopsy, and measurements of serum folate and vitamin $B_{12}$ levels were performed on those subjects in whom there was clinical or electrophysiological evidence of peripheral neuropathy.

NERVE CONDUCTION STUDIES Electrophysiological studi were performed on 62 subjects with lymphoma and of 35 control subjects. The control subjects had no histor $\mathbb{D}$ of a neurological disorder, and were normal on clinicad examination. The ages of the lymphoma patients ranged from 14 to 83 years, and those of the control group ranged from 18 to 80 years. The patients and contro subjects were separated into two groups on the basis of age. There were 20 patients under the age of 50 , and 42 patients over the age of 50 . The mean ages of the patients and controls in the four groups are given in Table 2.

Motor conduction velocities were determined in the median, ulnar, and lateral popliteal nerves. Action potentials were recorded through surface electrodes placed over the abductor pollicis brevis, abductor digiti minimi, and extensor digitorum brevis muscles respectively following supramaximal stimulation of the nerve through the skin at two places.

Sensory action potentials were recorded through surface electrodes placed over the median and ulnar nerves at the wrist on stimulating the index and little fingers respectively with ring electrodes (Dawson, 1956). The mixed motor and sensory nerve action potential was recorded with surface electrodes from the ulnar nerve above the level of the elbow on stimulating at the wrist (Gilliatt and Sears, 1958). The mixed nerve action potential was recorded from the lateral popliteal nerve with needle electrodes inserted at the neck of the fibula on stimulating the anterior tibial nerve at the ankle (Gilliatt, Goodman, and Willison, 1961).

The stimulus was a square wave of duration $0.2 \mathrm{msec}$ derived from a Disa Ministim. The recording electrodes were connected to a Tektronix FM 122 pre-amplifier and the action potentials were displayed on the upper beam 
of a Tektronix 502 A oscilloscope; a time-scale derived from a Digitimer (Devices Ltd.) was displayed on the lower beam. Photographic records were made on $35 \mathrm{~mm}$ film. The skin temperature of the upper and lower extremities was measured with a thermistor and ranged from $31^{\circ} \mathrm{C}$ to $35^{\circ} \mathrm{C}$.

HISTOLOGICAL METHODS Sural nerve biopsy was performed on five patients with lymphoma who had abnormalities of nerve conduction. The sural nerve was removed at necropsy from six control subjects.

Light microscopy The nerves were divided into three pieces each about $1 \mathrm{~cm}$ in length and attached to card to preserve the original length. One piece was fixed in Flemming's solution for $\mathbf{2 4}$ hours, dehydrated in alcohol, embedded in paraffin wax, and cut transversely in serial sections of $5 \mu$ thickness. The sections were stained with Kultschitsky's haematoxylin and counterstained with van Gieson stain (Gutmann and Sanders, 1943). Photomicrographs of selected fascicles were printed on photographic paper at an enlargement of $\times 1,000$. The external diameter of all myelinated fibres not undergoing active degeneration was measured with a rule and the total number of fibres was counted. The area of the fascicles was measured with a planimeter and the fibre density was calculated as the number of fibres per sq. $\mathrm{mm}$ of intraperineural area (Swallow, 1966). Histograms of fibre size were constructed according to the methods of Swallow (1966) and Fullerton and O'Sullivan (1968). Fibres of external diameter $2 \mu$ or less were grouped together, and larger fibres were subdivided into $1 \mu$ groups.

A second piece of each nerve was fixed in picric acid (Holmes, 1943), embedded in paraffin wax and cut transversely and longitudinally in sections of $5 \mu$ thickness. The sections were stained with haematoxylin and eosin, and with Congo Red.

A third piece of each nerve was fixed in $10 \%$ formol saline and part of it subsequently stained for 24 hours in $1 \%$ osmic acid. The specimen was washed, and macerated for 24 hours in a mixture of two parts glycerol to one part water. Single fibres were isolated by the method described by Thomas (1955). Thirty to 40 fibres were isolated from each nerve. Fibres were selected to cover the range of fibre diameters, rather than to isolate those fibres that were obviously abnormal. Measurements were made of the length and diameter of each internode (Vizoso and Young, 1948) and the results plotted graphically to show the relationship of internodal length to fibre diameter in the manner described by Fullerton, Gilliatt, Lascelles, and Morgan-Hughes (1965).

ELECTRON MICROSCOPY Pieces of nerve $5 \mathrm{~mm}$ in length from four patients with lymphoma and from one control subject were fixed in iced $2 \%$ osmic acid in $0.1 \mathrm{M}$ Cacodylate buffer ( $\mathrm{pH} 7 \cdot 3)$ for three hours. The specimens were then separated into fascicles under the dissecting microscope to facilitate orientation (Ochoa and Mair, 1969a), dehydrated, counterstained with $1 \%$ phosphotungstic acid in absolute alcohol and embedded in Araldite. Ultrathin sections were stained on copper grids with uranyl acetate and lead citrate, and examined in a Philips EM200 electron microscope. Unmyelinated fibres were counted and their diameters measured on prints at a final enlargement of about $\times 6,000$. Fibres of diameter $0.2 \mu$ or less were grouped together, and larger fibres subdivided into $\mathbf{0 . 2} \mu$ groups (Ochoa and Mair, 1969a). The number of Schwann cell nuclei and fibroblast nuclei was also counted. The exact final enlargement was determined by photographing a ruled diffraction grating, and subjecting the plate to the same processes of developing and printing. Densities of the various elements were calculated as numbers per sq. $\mathrm{mm}$.

\section{RESULTS}

CLINICAL STUdies Sixty-two subjects were selected for electrophysiological studies, after exclusion of subjects with a history of alcoholism, inadequate diet, diabetes mellitus, or of peripheral vascular disease. With the exception of four subjects who had received an injection of nitrogen mustard in the past, and three subjects who were under treatment with chlorambucil, none of the subjects had received cytotoxic drugs. Subjects who had received vincristine or vinblastine were excluded from the study. Five subjects had clinical evidence of a mild peripheral neuropathy (Table 1) but the remaining subjects were clinically normal. The stage of the malignant disease varied widely among the subjects but none of the subjects was either grossly wasted or in the terminal stages of the disease.

TABLE 1

PERIPHERAL NERVE INVOLVEMENT IN 62 SUBJECTS WI1H MALIGNANT LYMPHOMA

\begin{tabular}{lccc}
\hline \multicolumn{1}{c}{ Diagnosis } & $\begin{array}{c}\text { Patients } \\
(\text { no. })\end{array}$ & $\begin{array}{c}\text { Mild } \\
\text { clinical } \\
\text { neuropathy }\end{array}$ & $\begin{array}{c}\text { Generalized } \\
\text { impairment } \\
\text { of nerve } \\
\text { conduction }\end{array}$ \\
\hline Hodgkin's disease & 20 & 1 & 4 \\
Chronic lymphatic leukaemia & 18 & 1 & 8 \\
Lymphosarcoma & 9 & 1 & 5 \\
Reticulum cell sarcoma & 10 & 2 & 5 \\
Giant follicular lymphoma & 5 & & 22 \\
\hline \multicolumn{1}{c}{ Totals } & 62 & 5 & \\
\hline
\end{tabular}

NERVE CONDUCTION STUDIES The results of nerve conduction studies are summarized in Table 2 , from which it may be seen that there was a significant increase in latency and decrease in amplitude of the sensory action potentials recorded from the median and ulnar nerves, and of the mixed motor and sensory action potentials recorded from the ulnar and lateral popliteal nerves in the subjects less than 50 years of age. The results were similar in the older subjects, but the increase in latency in the median nerve sensory action potential and in the lateral popliteal 
TABLE 2

MOTOR AND SENSORY CONDUCTION STUDIES IN 62 SUBJECTS WITH LYMPHOMA

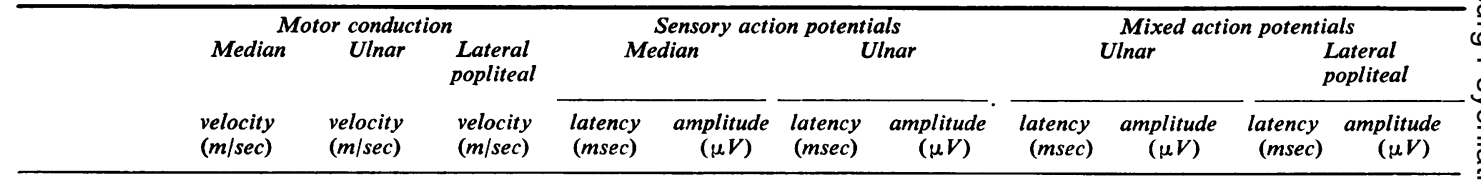

Group A: Subjects younger than 50 years

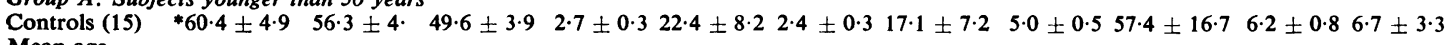
Mean age

$31 \cdot 7 \pm 10 \cdot 2$

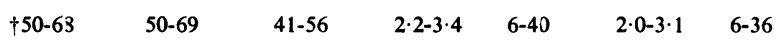

$4 \cdot 1-5 \cdot 8 \quad 35-88$

$5 \cdot 1-7 \cdot 2 \quad 3-13$

Lymphoma (20) $53.3 \pm 12 \cdot 3 \quad 55.5 \pm 7.9 \quad 44.4 \pm 5.1 \quad 3.4 \pm 0.7 \quad 11 \cdot 7 \pm 3.3 \quad 3.2 \pm 0.7 \quad 7 \cdot 1 \pm 2.8 \quad 5.5 \pm 0.8 \quad 29 \cdot 2 \pm 14.6 \quad 6 \cdot 8 \pm 0 \cdot 1 \quad 3.5 \pm 1.6 \quad 5$

Mean age

$34 \cdot 3 \pm 12 \cdot 2$

(14-50)

\begin{tabular}{|c|c|c|c|c|c|c|c|c|c|c|c|}
\hline$(14-50)$ & $42-65$ & $47-76$ & $34-55$ & $2 \cdot 6-5 \cdot 0$ & $7-20$ & $2 \cdot 6-4 \cdot 8$ & $2-12$ & $4 \cdot 2-7 \cdot 3$ & $6-62$ & $5 \cdot 6-8 \cdot 9$ & $0-7$ \\
\hline Significance & $P<0.05$ & ns & $P<0.01$ & $P<0.01$ & $P<0.001$ & $P<0.001$ & $P<0.001$ & $P<0.05$ & $P<0.001$ & $P<0.05$ & $P<0.01$ \\
\hline
\end{tabular}

Group B: Subjects older than 50 years

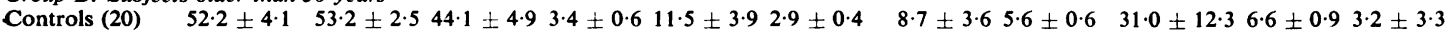

Mean age

$63.4 \pm 9.7$

(50-80)

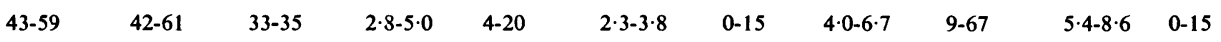

Lymphoma (42) $50.3 \pm 4.6 \quad 51.6 \pm 5.2 \quad 40.2 \pm 6.4 \quad 3.6 \pm 0.6 \quad 9.0 \pm 5.2 \quad 3.2 \pm 0.6 \quad 5.8 \pm 3.3 \quad 6.0 \pm 0.8 \quad 21 \cdot 3 \pm 10.2 \quad 6.7 \pm 0.8 \quad 3.5 \pm 0.907$

Mean age

$64 \cdot 6 \pm 9 \cdot 4$

(51-83)

\begin{tabular}{|c|c|c|c|c|c|c|c|c|c|c|c|}
\hline$(21-00)$ & $42-64$ & $36-61$ & $28-50$ & $2 \cdot 8-5 \cdot 0$ & $0-30$ & $2 \cdot 1 \cdot 4 \cdot 8$ & $0-34$ & $4 \cdot 1 \cdot 8 \cdot 0$ & $7-51$ & $5 \cdot 3-9 \cdot 0$ & $2 \cdot 3-4 \cdot 9 \mathbb{\mathrm { D }}$ \\
\hline Significance & ns & nิ & $P<0.05$ & ns & $P<0.01$ & $P<0.05$ & $P<0.01$ & $P<0.05$ & $P<0.01$ & ns & $P<0.0 ?$ \\
\hline
\end{tabular}

$\uparrow$ Range.

mixed action potential did not become significant. There is a tendency towards slower motor conduction in both age groups, but the impairment of motor conduction reaches levels of significance only in the median nerve of the younger age group, and in the lateral popliteal nerve of both age groups.

It may be seen from Table 1 that there was generalized impairment of conduction in 22 subjects. Only five of these subjects had clinical evidence of a mild neuropathy. Nerve conduction studies were within the normal range in six of the seven subjects who had received nitrogen mustard or chlorambucil.

SURAL NERVE BIOPSY Control subjects The sural nerve was removed at necropsy from six control subjects (mean age 40 years, range 13 to 54 years) and the number and density of myelinated fibres in one to two fascicles were measured. The mean value for myelinated fibre density was 4.37 thousand fibres/sq mm (range 3.81 to 6.42 thousand fibres/sq $\mathrm{mm})$. There was a bimodal distribution of myelinated fibres, with peaks at 3-6 $\mu$ and at 9-13 $\mu$. Single fibres were teased from each nerve, and the length and diameter of each internode were measured. Fibres in which there was evidence of segmental demyelination or of active axonal degeneration wert $\vec{\varphi}$ rarely found in the control nerves. A mean regression line and standard deviation for the relationship of 0 internodal length to fibre diameter was calculated from the measurements performed on the control nerves. Electron microscopy was performed on the sural nerve of a control subject, and the number and $\frac{}{\Phi}$ density of unmyelinated fibres, Schwann cell nuclei $\overrightarrow{\vec{B}}$ and fibroblast nuclei were calculated.

Subjects with lymphoma Sural nerve biopsy was performed on five subjects with lymphoma in whom electrophysiological studies had demonstrated impaired conduction. None of these subjects had received any form of cytotoxic therapy. One subject (case 1) had clinical evidence of mild peripheral neuropathy but the remaining four subjects had no abnormalities on neurological examination (Table

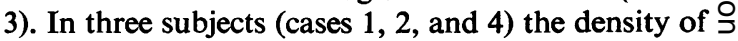
myelinated fibres was reduced, fibres of all diameters being affected (Fig. 1). The total fibre density was within the normal range in the two remaining $N$ subjects. There was no evidence of amyloid, arteritis, or cellular infiltration in any of the nerves examined. Abnormalities were found in all nerves on $\omega$ 
TABLE 3

SURAL NERVE DATA FROM FIVE SUBJECTS WITH LYMPHOMA

\begin{tabular}{|c|c|c|c|c|c|c|c|c|}
\hline Case & Age & $\operatorname{Sex}$ & Diagnosis & $\begin{array}{c}\text { Clinical } \\
\text { neuropathy }\end{array}$ & $\begin{array}{l}\text { Impaired } \\
\text { conduction }\end{array}$ & $\begin{array}{c}\text { Density of } \\
\text { myelinated fibres } \\
\text { (thousands/sq } \mathrm{mm} \text { ) }\end{array}$ & $\begin{array}{c}\text { Area } \\
(s q \mathrm{~mm})\end{array}$ & Teased fibres \\
\hline 1 & 76 & $\mathbf{M}$ & Chronic lymphatic leukaemia & + & + & $2 \cdot 40$ & $0 \cdot 27$ & $\begin{array}{l}\text { Active axonal degeneration and } \\
\text { segmental demyelination }\end{array}$ \\
\hline 2 & 60 & $\mathbf{M}$ & Reticulum cell sarcoma & - & + & $1 \cdot 80$ & 0.26 & Segmental demyelination \\
\hline 3 & 42 & $\mathbf{M}$ & Reticulum cell sarcoma & - & + & 6.07 & 0.23 & Active axonal degeneration \\
\hline 4 & 75 & $\mathbf{M}$ & Hodgkin's disease & - & + & $1 \cdot 55$ & 0.59 & $\begin{array}{l}\text { Segmental demyelination and } \\
\text { occasional axonal degeneration }\end{array}$ \\
\hline 5 & 40 & $\mathbf{M}$ & Lymphosarcoma & - & + & $5 \cdot 51$ & 0.09 & $\begin{array}{l}\text { Segmental demyelination, and } \\
\text { occasional active axonal } \\
\text { degeneration }\end{array}$ \\
\hline
\end{tabular}

examination of teased fibre preparations. In two subjects (cases 2 and 5) numerous fibres undergoing segmental demyelination and remyelination were seen (Figs. 2 and 3). Only an occasional fibre was
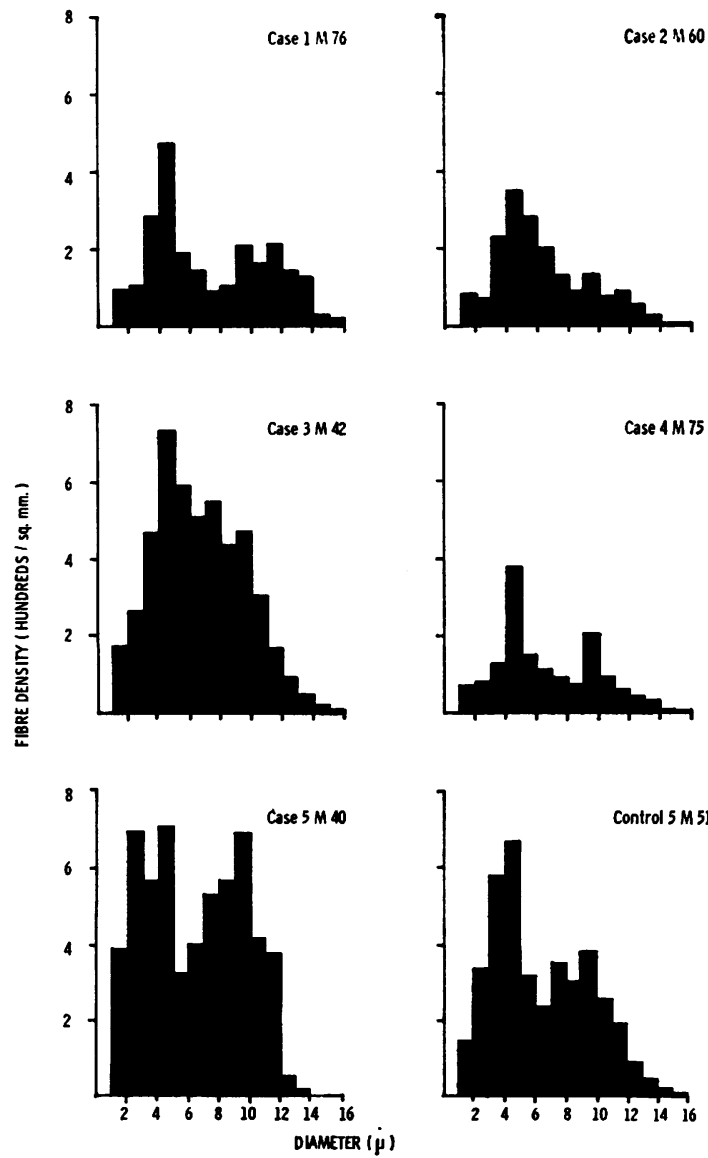

FIG. 1. Histograms of fibre diameter distribution of myelinated fibres in five subjects with lymphoma and in a control subject.

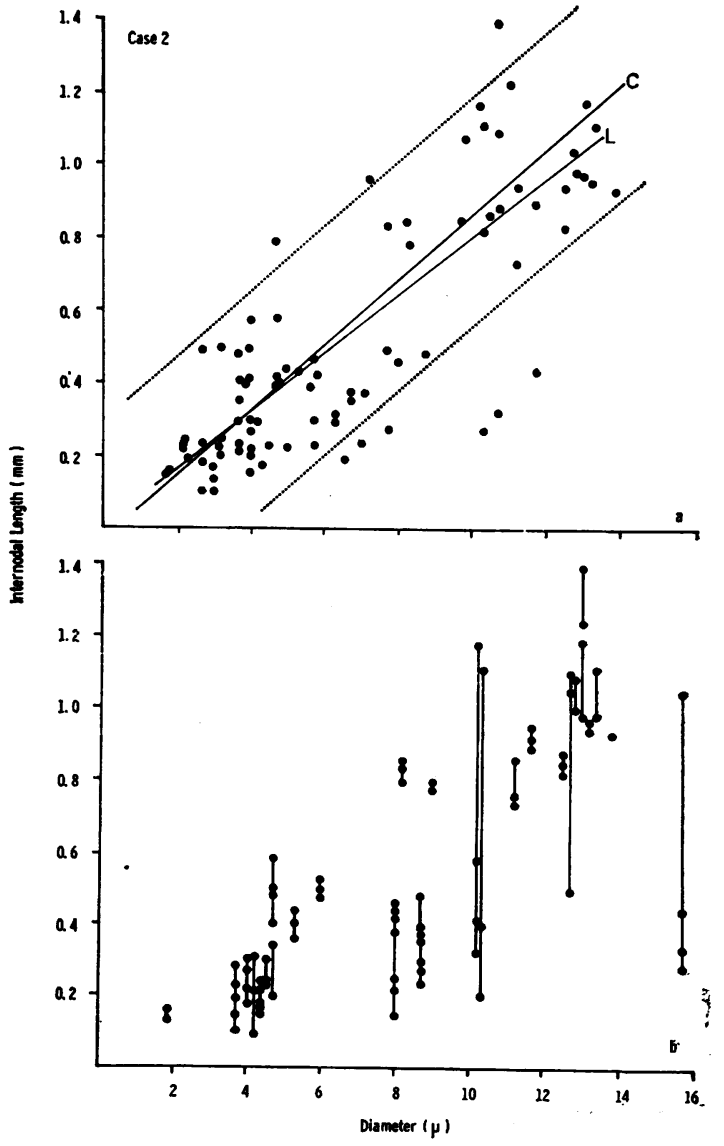

FIG. 2 (a. above). The relationship of internodal length to fibre diameter, and the calculated regression line (L) in case 2. The regression line for six control nerves is indicated (C) and two standard deviations are indicated by the dotted lines. (b. below.) Distribution of internodal lengths of individual fibres. The internodal lengths of individual fibres are plotted against the diameter of the widest internode and joined by a vertical line. 


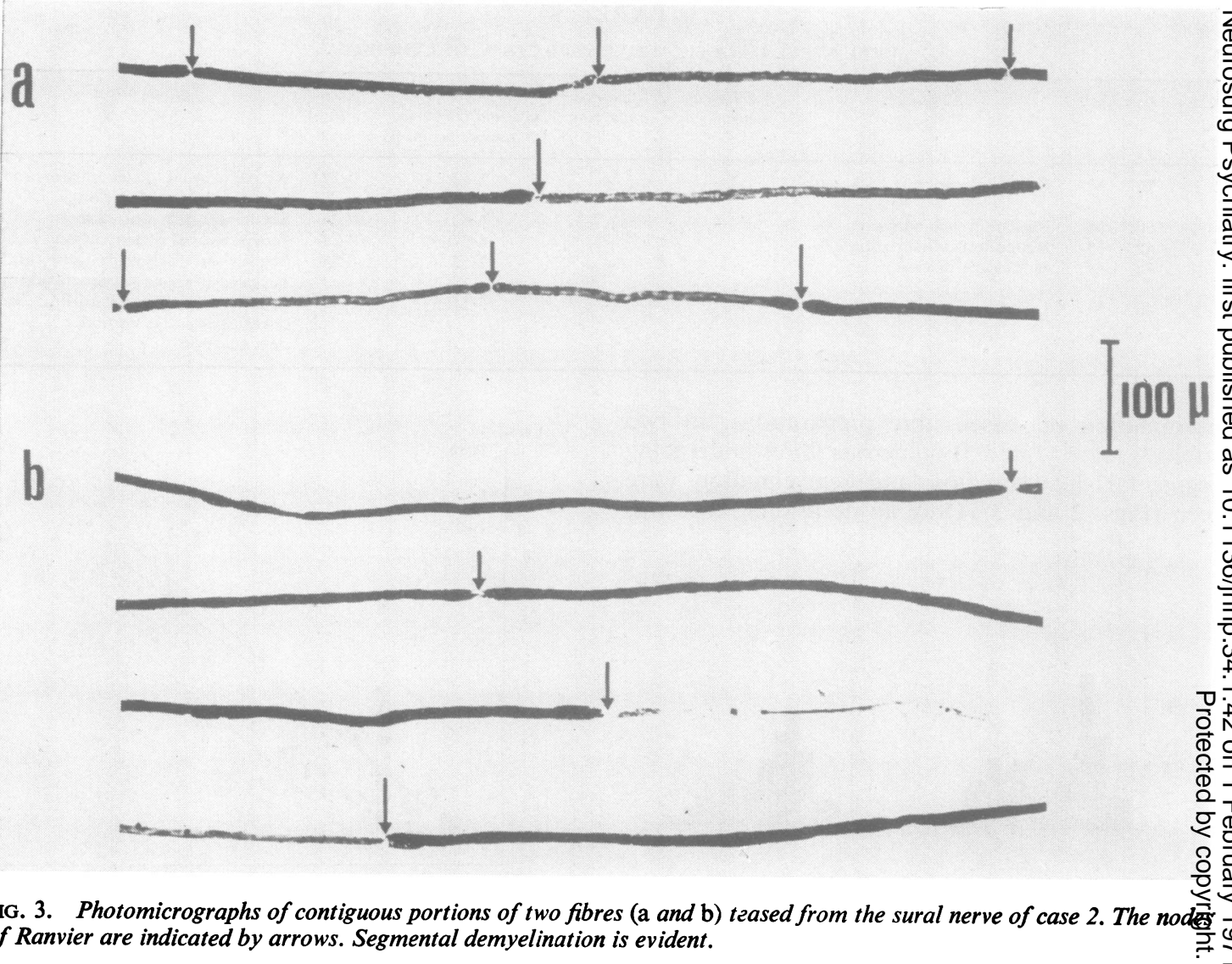

found to be undergoing active axonal degeneration. In one subject (case 3) active axonal degeneration was the predominant pathological abnormality. There was little variation of internodal length on individual fibres but the internodes on some fibres were unusually short (Fig. 4) suggesting that some regeneration had occurred. In the remaining two subjects (cases 1 and 4), both of whom were over the age of 70, fibres undergoing axonal degeneration and segmental demyelination were seen.

Electron microscopy was performed on nerves from four of the subjects with lymphoma, and the density of unmyelinated fibres, Schwann cell nuclei, and fibroblast nuclei was measured (Table 4, Fig. 5). The density of unmyelinated fibres was within the range reported in five control subjects by Ochoa and Mair (1969a, b). The density of Schwann cell nuclei in the control subject and in three of the four lymphoma subjects exceeded the upper limits of the normal range of Ochoa and Mair (1969a).

In one subject (case 2) in whose sural nerve segmental demyelination was present in teased single fibre preparations, several small concentric configurations composed of Schwann cell processes and $\frac{\otimes}{\varnothing}$ collagen fibres were found enveloping fully my- $\unrhd$ elinated fibres on electron microscopy (Fig. 6). $\overrightarrow{\bar{o}}$ These small onion bulb formations were not found in the other nerves examined.

\section{DISCUSSION}

Clinical and electrophysiological studies have been $\frac{0}{2}$ performed on 62 patients with malignant lymphoma, of whom $22(35 \%)$ had evidence of a peripheral 8 neuropathy. Five of the affected subjects had $₹$ clinical evidence of a mild peripheral neuropathy 을 but the remaining 17 patients had no abnormality of the peripheral nervous system on neurological o examination. Abnormalities of conduction were more common in patients with lymphosarcoma and $\sigma$ reticulum cell sarcoma than in those with other forms $N$ of lymphoma. The presence of impaired conduction 


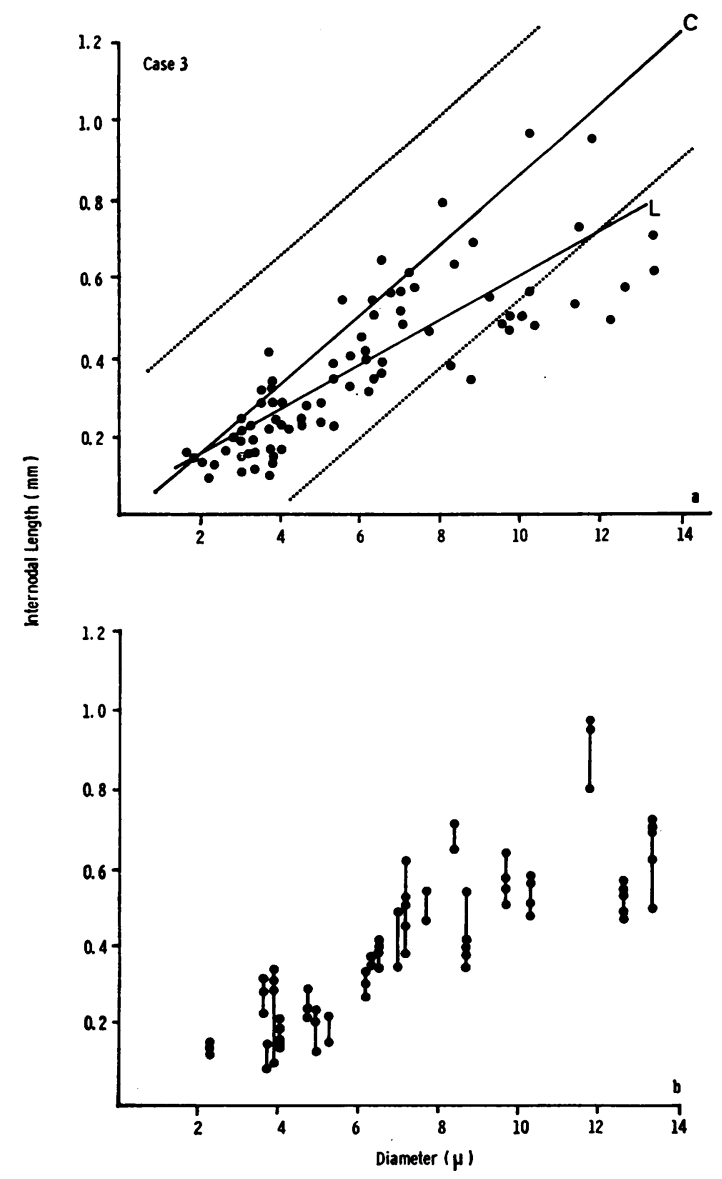

FIG. 4. Measurements of internodal length and fibre diameter from the sural nerve biopsy of case 3. The results are plotted in the same manner as in Fig. 2.

TABLE 4

DENSITY OF UNMYELINATED FIBRES, SCHWANN CELL NUCLEI AND FIBROBLAST NUCLEI IN FOUR SUBJECTS WITH LYMPHOMA, AND IN A CONTROL SUBJECT

\begin{tabular}{lcccc}
\hline Patients & $\begin{array}{c}\text { Area } \\
(s q \mu)\end{array}$ & $\begin{array}{c}\text { Density of } \\
\text { unmyelinated } \\
\text { fibres } \\
\text { thousands/ } \\
\text { sq } \text { mm })\end{array}$ & $\begin{array}{c}\text { Density of } \\
\text { Schwann } \\
\text { nuclei } \\
(/ \text { sq } \text { mm })\end{array}$ & $\begin{array}{c}\text { Density of } \\
\text { fibroblast } \\
\text { nuclei } \\
(/ \text { sq mm })\end{array}$ \\
\hline Control & 10,000 & $39 \cdot 8$ & 3,200 & 300 \\
Case 1 & 10,200 & $28 \cdot 5$ & 3,430 & 880 \\
Case 2 & 10,200 & $39 \cdot 9$ & 3,517 & 590 \\
Case 3 & 9,840 & $34 \cdot 2$ & 4,472 & 0 \\
Case 5 & 8,500 & $33 \cdot 1$ & 1,880 & 590 \\
Range & & & & \\
(Ochoa and Mair, & & $21 \cdot 8-33 \cdot 9$ & $1,729-2,762$ & $0-408$ \\
1969a) & & & & \\
\hline
\end{tabular}
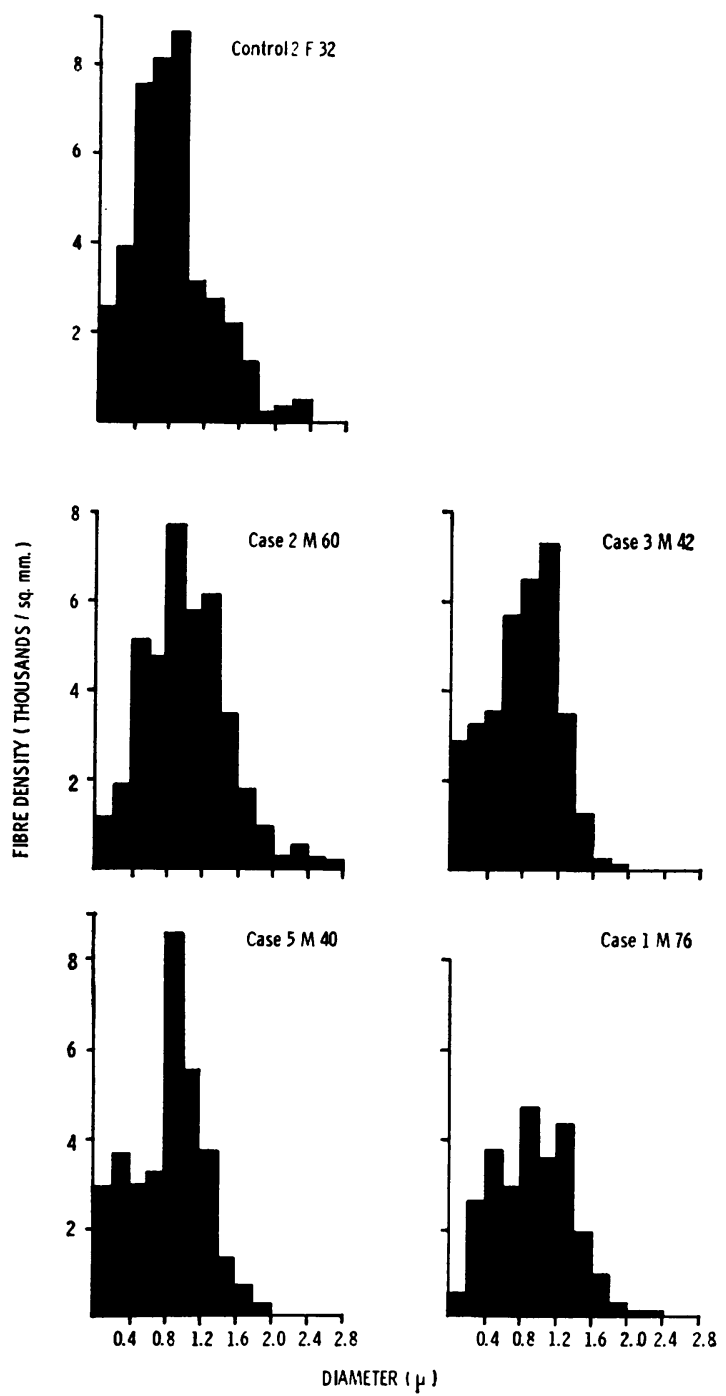

FIG. 5. Histograms of fibre diameter of unmyelinated fibres in four subjects with lymphoma and in a control subject.

was not related to the clinical stage of the malignant disorder. It is of interest that in a retrospective study of 3,725 patients with malignant lymphoma, Williams, Diamond, Craver, and Parsons (1959) reported only three subjects with clinical evidence of a symmetrical peripheral neuropathy.

In only one of the affected subjects in the present series was there a history of previous treatment with a cytotoxic drug. This subject had received nitrogen mustard, which has not been reported to cause a 


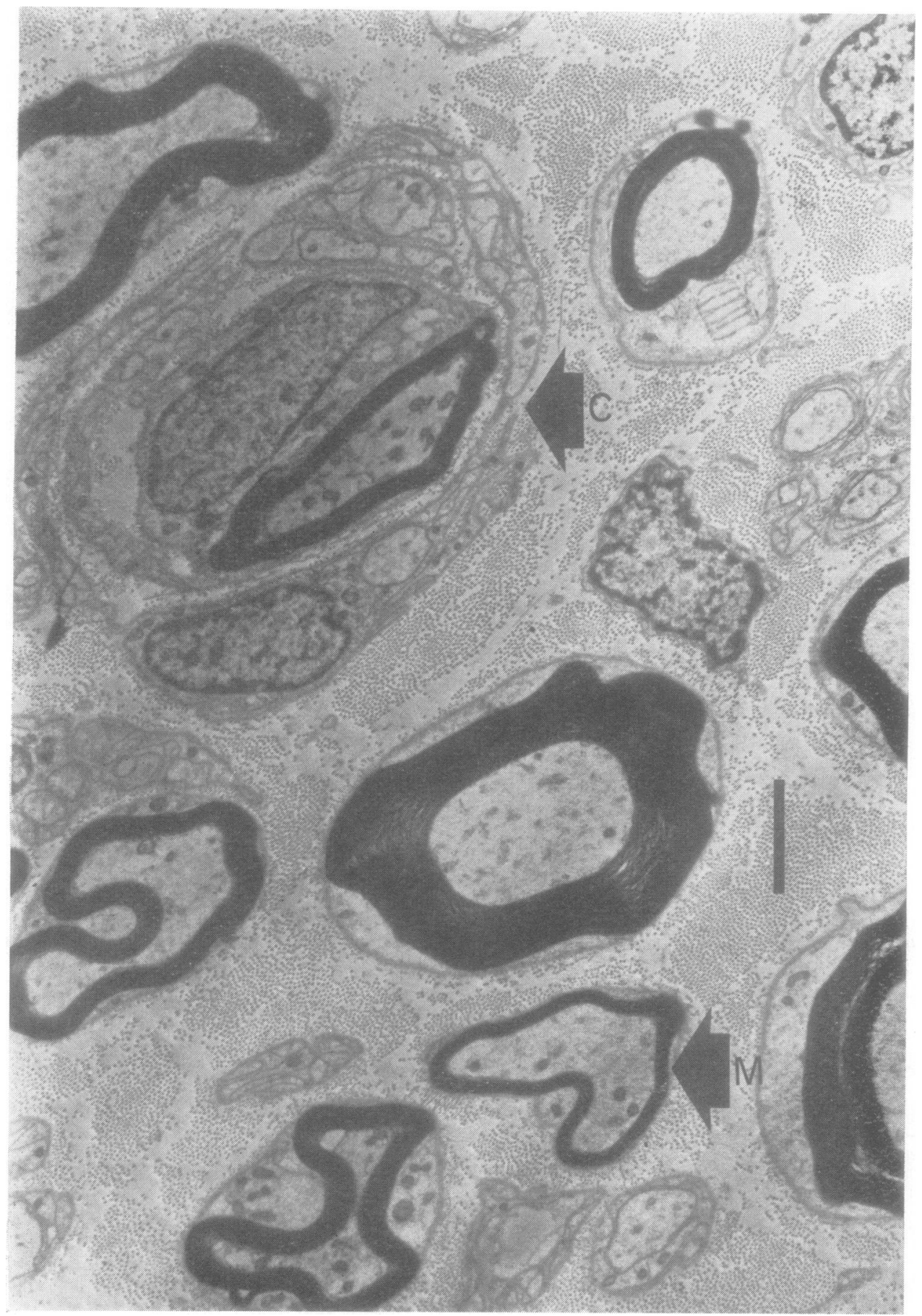

FIG. 6. Electronmicrograph of a transverse section of sural nerve from case 2. A small concentric configuration (C) and thinly myelinated axon (M) are indicated. Scale: $2 \mu$. 
peripheral neuropathy. None of the subjects had been treated with the Vinca alkaloids and it is considered that therapy with cytotoxic drugs did not contribute to the impairment of nerve conduction. Subjects with diabetes mellitus, alcoholism, vascular disease, nutritional deficiency, uraemia, or vitamin $B_{12}$ deficiency were excluded from the study on the basis of history and laboratory investigations.

It is well known that a progressive impairment of nerve conduction occurs with ageing (Gilliatt et al., 1961). However, the impairment of conduction demonstrated in patients with lymphoma was not related to their age, and significant abnormalities were found in the younger group of subjects.

The pathological changes found on examination of the sural nerve were those of axonal degeneration and segmental demyelination.

It is difficult to assess the significance of the pathological abnormalities in the sural nerves of the two patients over the age of 70 , since axonal degeneration and segmental demyelination may be found in nerves from control subjects in this age group (Lascelles and Thomas, 1966; Arnold and Harriman, 1970). However, the pathological abnormalities seen in the nerves of the three younger subjects were considerably more extensive than were found in nerves from control subjects of similar ages. The density and distribution of unmyelinated fibres seen electronmicroscopically was within the range reported by Ochoa and Mair (1969a) for control subjects and it is concluded that no significant degeneration or regeneration of unmyelinated fibres had occurred. In one subject with segmental demyelination there were small onion bulb formations associated with fully myelinated fibres, but there were no other significant abnormalities found on electron microscopy. None of the nerves studied had evidence of cellular infiltration, amyloid deposition, or vasculitis.

The finding of axonal degeneration suggests that some toxic or metabolic process has affected the nerve cell; a relative nutritional deficiency may be a factor in the production of malignant neuropathy, and it is established that nutritional deficiency results in axonal degeneration (Pekelharing and Winkler, 1893; Dyck, Gutrecht, Bastron, Karnes, and Dale, 1968; Walsh and McLeod, 1970).

There have been very few detailed pathological studies performed on the peripheral nervous system of patients with malignant lymphoma. In some cases (Blanchard, 1962) no abnormality could be found, but both multiple root infiltration (Allison and Gordon, 1955) and multiple microemboli in nerves (Barron, Rowland, and Zimmerman, 1960) have been reported. Both types of lesion would result in the changes of axonal degeneration in the peri- pheral nerve biopsy. However, the high incidence of peripheral neuropathy in patients with no clinical evidence of widespread invasion suggests that a toxic or metabolic factor is more likely to be responsible in these subjects. The finding of segmental demyelination indicates a disorder of the Schwann cell, and was found to involve numerous fibres in two of the subjects studied. The mechanisms already described do not explain the finding of segmental demyelination in the peripheral nerve biopsy and it is suggested that a toxic or metabolic disorder of the Schwann cell may occur in the malignant lymphomas.

The work was supported by grants from the N.S.W. State Cancer Council, the Cancer Research Fund, University of Sydney, and from the Postgraduate Medical Foundation of the University of Sydney. Invaluable technical assistance was given by Miss Julia Baverstock. The advice and criticism of Dr. J. G. McLeod is gratefully acknowledged.

\section{REFERENCES}

Allison, R. S., and Gordon, D. S. (1955). Reticulosis of the nervous system simulating acute infective polyneuritis. Lancet, 2, 120-122.

Arnold, N., and Harriman, D. G. F. (1970). The incidence of abnormality in control human peripheral nerves studied by single axon dissection. J. Neurol. Neurosurg. Psychiat., $33,55-61$.

Barron, K. D., Rowland, L. P., and Zimmerman, H. M. (1960). Neuropathy with malignant tumour metastases. J. nerv. ment. Dis., 131, 10-31.

Blanchard, B. M. (1962). Peripheral neuropathy (noninvasive) associated with lymphoma. Ann. int. Med., 56, 774-778.

Dawson, G. D. (1956). The relative excitability and conduction velocity of sensory and motor nerve fibres in man. J. Physiol. (Lond.), 131, 436-451.

Denny-Brown, D. (1948). Primary sensory neuropathy with muscular changes associated with carcinoma. J. Neurol. Neurosurg. Psychiat., 11, 73-87.

Dyck, P. J., Gutrecht, J. A., Bastron, J. A., Karnes, W. E., and Dale, A. J. D. (1968). Histologic and teased-fiber measurements of sural nerve in disorders of lower motor and primary sensory neurons. Mayo Clin. Proc., 43, 81-123.

Fullerton, P. M., Gilliatt, R. W., Lascelles, R. G., and Morgan-Hughes, J. A. (1965). The relation between fibre diameter and internodal length in chronic neuropathy. J. Physiol. (Lond.), 178, 26P-28P.

Fullerton, P. M., and O'Sullivan, D. J. (1968). Thalidomide neuropathy: a clinical, electrophysiological and histological follow-up study. J. Neurol. Neurosurg. Psychiat., 31, 543-551.

Gilliatt, R. W., Goodman, H. V., and Willison, R. G. (1961). The recording of lateral popliteal nerve action potentials in man. J. Neurol. Neurosurg. Psychiat., 24, 305-318.

Gilliatt, R. W., and Sears, T. A. (1958). Sensory nerve action potentials in patients with peripheral nerve lesions. $J$. Neurol. Neurosurg. Psychiat., 21, 109-118.

Gutmann, E., and Sanders, F. K. (1943). Recovery of fibre numbers and diameters in the regeneration of peripheral nerves. J. Physiol. (Lond.), 101, 489-518.

Hild zbrand, J., and Coërs, C. (1967). The neuromuscular 
function in patients with malignant tumours. Electromyographic and histological study. Brain, 90, 67-82.

Holmes, W. (1943). Silver staining of nerve axons in paraffin sections. Anat. Rec., 86, 157-187.

Hutchinson, E. C., Leonard, B. J., Maudsley, C., and Yates, P. O. (1958). Neurological complications of the reticuloses. Brain, 81, 75-92.

Lascelles, R. G., and Thomas, P. K. (1966). Changes due to age in internodal length in the sural nerve in man. $J$. Neurol. Neurosurg. Psychiat., 29, 40-44.

Moody, J. F. (1965). Electrophysiological investigations into the neurological complications of carcinoma. Brain, 88, 1023-1036.

Ochoa, J., and Mair, W. G. P. (1969a). The normal sural nerve in man. I. Ultrastructure and numbers of fibres and cells. Acta neuropath. (Berl.), 13, 197-216.

Ochoa, J., and Mair, W. G. P. (1969b). The normal sural nerve in man. II. Changes in the axons and Schwann cells due to ageing. Acta neuropath. (Berl.), 13, 217-239.

O'Sullivan, D. J., and Swallow, M. (1968). The fibre size and content of the radial and sural nerves. J. Neurol. Neurosurg. Psychiat., 31, 464-470.

Pekelharing, C. A., and Winkler, C. (1893). Beri Beri:
Researches Concerning its Nature and Cause and the $\bar{Z}$ Means of Its Arrest. Young J. Pentland: Edinburgh. (D Simpson, J. A. (1962). The neuropathies. Modern Trends in Neurology, Vol. 3, p. 245. Edited by D. Williams. @ Butterworths: London.

Swallow, M. (1966). Fibre size and content of the anterior tibial nerve of the foot. J. Neurol. Neurosurg. Psychiat., 29, 205-213.

Thomas, P. K. (1955). Growth changes in the myelin sheath of peripheral nerve fibres in fishes. Proc. roy. Soc. B., 143, 380-391.

Trojaborg, W., Frantzen, E., and Andercon, I. (1969). Peripheral neuropathy and myopathy associated with $\overline{\overline{\bar{S}}}$ carcinoma of the lung. Brain, 92, 71-82.

Walsh, J. C., and McLeod, J. G. (1970). Alcoholic neuropathy. An electrophysiological and histological study. 흐 J. neurol. Sci., 10, 457-469.

Williams, H. M., Diamond, H. D., Craver, L. F., and $\vec{\partial}$ Parsons, H. (1959). Neurological Complications of Lymph- $\varrho$ omas and Leukemias. Thomas: Springfield.

Vizoso, A. D., and Young, J. Z. (1948). Internode length and fibre diameter in developing and regenerating nerves. $\vec{\circ}$ J. Anat., 82, 110-134. 